\title{
RETINAL DEGENERATION IN HEREDITARY ATAXIA
}

\author{
BY
}

\section{Å. BJÖRK, U. LINDBLOM, and L. WADENSTEN}

\author{
From the Eye Clinic, Karolinska Hospital, and the Neurological Clinic, Serafimerlasarettet, Stockholm
}

Deterioration of vision is a not infrequent occurrence in cases of hereditary ataxia. Like the ataxic symptoms it is progressive and may become severe. According to the literature the deterioration of vision has been ascribed to optic atrophy in the majority of cases and only in a few instances are retinal changes or cataract described. It is obvious, however, that the actual findings have often been very slight and that in some cases the ophthalmoscopical picture has been recorded as normal despite a strong reduction in visual acuity (Bell and Carmichael, 1939; van Bogaert, 1948).

The present study gives an account of five cases of hereditary ataxia associated with serious loss of vision. The patients have been subjected to careful examination including electroretinography(E.R.G.) in four of the cases. This examination has revealed new facts that elucidate the problems associated with the causation and progression of impairment of vision in this disorder.

\footnotetext{
Methods

Each patient was subjected to exhaustive neurological and ophthalmological examination. The visual fields were generally studied in a perimeter of hemispherical form (model Haag and Streit) with a circular white test object of $0.5 \mathrm{~cm}$. in diameter. The light sense was tested by determining the minimum perceptible after 30 minutes of dark
}

38 Lux

95 Lux adaptation using Carle's modification of the Gullstran photometer. The colour sense was investigated by mean $\overline{\text {. }}$. of pseudo-isochromatic tables and the Nagel anomalod scope.

The E.R.G. was recorded by Karpe's $(1945,1948 \%$ technique, with a contact glass filled with physiologicab saline covering the corneal surface as the active electrode; a second electrode being attached to the forehead. The् potentials were fed to a condenser-coupled amplifier and? the records were made on moving paper film by means of two oscillographs, one for the actual E.R.G. and the other for the light stimulus. When single-flash E.R.G $\overrightarrow{0}$ was to be studied the stimulus consisted of a short flasif of "white light" of about $\frac{1}{17}$ second duration. The्e light intensities were used: 20,80 , and 800 lux wer measured at the plane of the eye. In flicker E.R.G. 零e
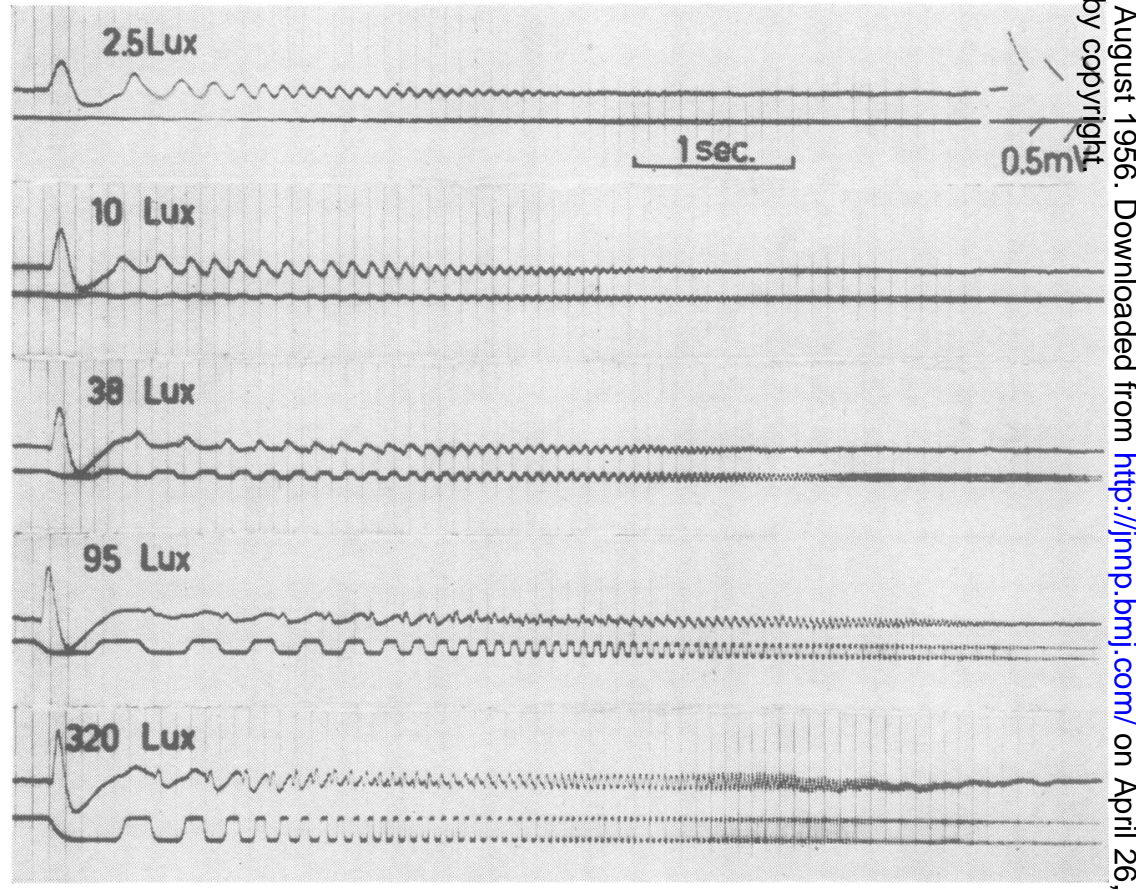

FIG. 1.-Flicker E.R.G. from standard case. Flicker of scotopic type at low illumination intensities $\mathrm{N}$ of photopic type at high intensities. Flicker fusion frequency increasing from 15 per sec. at low lus values to about 70 at maximum illumination. 
technique described by Dodt and Wadensten (1954) was used. The stimulus was produced by hand rotation of a sectored disc which interrupted a maintained light. Each period of illumination was followed by an equally long period of darkness. The flicker was varied with respect to frequency as well as to intensity of illumination, the latter varying from 1 to 400 lux.

Single-flash E.R.G. in man, as recorded according to Karpe, normally shows a high positive potential (b-potential) of a mean amplitude of $0.34 \mathrm{mV}$, sigma being $0.06 \mathrm{mV}$. In the following cases the mean amplitude has been statistically classified as follows:

$\mathrm{m} \pm 3 \sigma$ is almost certainly abnormal outside the limits (below $\mathrm{m}-3 \sigma$ is a "subnormal " E.R.G.).

$\mathrm{m} \pm 2 \cdot 5 \sigma$ is very probably abnormal outside the limits. $\mathrm{m} \pm 2 \sigma$ is probably abnormal outside the limits.

A relationship between the magnitude of the b-potential and the activity of the rod system has been established by experiments on animals and clinical investigations ( $c f$. , Granit, 1947; Karpe, 1945; Karpe and Tansley, 1948).

In interpreting the flicker E.R.G. special attention is given to the flicker fusion frequency (F.F.F.) and to the shape of the flicker waves. Flicker fusion frequency has been defined as the highest stimulus frequency at which every flash is still accompanied by a wave, and it is generally seen that the higher the F.F.F. the stronger the stimulant illumination used. Fig. 1 shows how the normal flicker E.R.G. changes with increasing stimulus intensity. At low intensities there are small rounded b-waves and the F.F.F. does not exceed 25 per second (scotopic flicker). At higher intensities the b-waves are more pointed and are interspersed with small negative a-waves, and the F.F.F. is high, up to about 70 per second (photopic flicker).

Experiments on animals have shown that the scotopic flicker is related to the rod function and the photopic flicker to the cone function of the retina ( $c f$. Granit, 1947). In accordance with this it has been found that cases of total colour blindness produce a flicker E.R.G. of purely scotopic type (Dodt and Wadensten, 1954; Wadensten, 1954, 1956).

It may be of value to point out here that neither single-flash E.R.G.s nor flicker E.R.G.s are influenced by lesions concerned with the visual paths only, e.g., a descending optic atrophy; but that they only reflect retinal changes. Furthermore, only extensive retinal lesions seem to influence the E.R.G. Hence neither isolated macular lesions nor limited retinal lesions of other types cause changes in the E.R.G. (Karpe, 1945, 1955; Wadensten, 1956).

\section{Case Reports}

Case 1.-A Hj-m, a woman, born in 1939 (No. 140/55), had healthy maternal grandparents, and no nervous disease was known among relatives except in the case of the mother, who was treated in 1938 (No. 519/38) in the Neurological Clinic for syndroma cerebellare progressivum and atrophia retinae.

When examined in 1938 her mother was 21 years old and her ophthalmological state was described thus: "Visual acuity 0.1 in both eyes; visual fields for white normal; total colour blindness; fundi, a manifest retinal atrophy affecting both eyes and especially clearly seen in the pigment layer. Blood vessels very narrow. Moderate atrophy of papillae, probably secondary to the retinal changes. Maculae show the same changes as other parts of the fundi and, further, creased macular reflexes as after a macular oedema." Deterioration of vision had been noticeable at the age of 10 , and since the age of 14 or 15 she had experienced difficulty in keeping her balance and during the last year her gait had been unsteady.

At a neurological examination of Case 1 in 1955 the gait was jerky, with side-stepping and a positive Romberg's sign. Diadochokinesis was impaired on both sides. In the finger-nose and knee-heel tests a slight trembling occurred towards the end of the movement, but this was not necessarily pathological. Muscular reflexes generally were lively, particularly in the legs. Babinski's sign was negative on both sides. Sensibility, gross power, and cranial nerves seemed to be normal; caloric nystagmus movements were slower than normal. $X$-ray examination of the skull was normal, and the E.E.G. showed moderate non-specific abnormality without any definite localization. Her psychic state was normal. The internal organs were normal, there was no endocrine disorder. Blood tests for syphilis were negative.

At an ophthalmological examination in 1949 the visual acuity was $\mathbf{0 . 5}$ for each eye. It has diminished gradually since then, values being 0.3 for each eye in 1950 , and $0 \cdot 2$ (right) and $0 \cdot 1$ (left) in 1951. In 1952 an examination showed 0.1 on each eye, a value that has since then remained almost unchanged. There was no refraction anomaly of importance.

Starting in 1951, exhaustive examinations, including E.R.G., were performed almost every year. At the beginning the ophthalmoscopical examination showed the fundi to be quite normal. At the examination in 1953 the vessels were somewhat narrow, and the structure of the retina seemed to be slightly granular. These findings were more distinct at the most recent examination (1955). There seemed to be an increase in pigmentation both peripherally and within the maculae.

The visual fields for white showed normal limits in 1953 but in 1955 there was a moderate narrowing of the fields in both eyes. The light sense, last tested in 1954, showed nothing definitely abnormal. The colour sense as tested with pseudo-isochromatic plates was already defective in 1951. Anomaloscope examination in 1953 resulted in equations suggesting total colour blindness.

A single-flash E.R.G. was recorded on four occasions. The following table shows the amplitudes of the bpotential as recorded in the different examinations (mean values) :

$$
\begin{aligned}
& 1951 \text { (right) } 0.32 \mathrm{mV} \text { (left) } 0.35 \mathrm{mV} \\
& 1953 \text { (right) } 0.33 \mathrm{mV} \text { (left) } 0.28 \mathrm{mV} \\
& 1954 \text { (right) } 0.27 \mathrm{mV} \text { (left) } 0.26 \mathrm{mV} \text { (see Fig. 2) } \\
& 1955 \text { (right) } 0.23 \mathrm{mV} \text { (left) } 0.21 \mathrm{mV}
\end{aligned}
$$

The intensity of the illumination was 20 lux in each case.

Although all values are probably normal the continuous decrease in amplitude is striking.

In the last three examinations, flicker E.R.G.s were included. Already in 1953 the flicker E.R.G. disclosed 


\section{LUx}
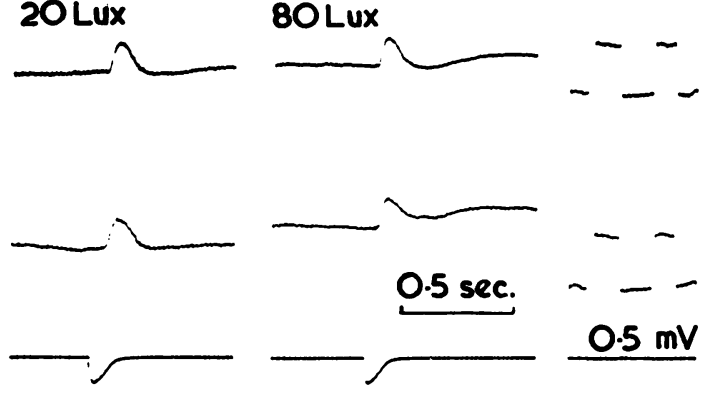

FIG. 2.-Case 1 (1954). Single flash E.R.G. from right (upper curve) and left eye (middle curve) at 20 and 80 lux. Flash recorded by lower curve. Amplitudes of b-waves at 20 lux are $0.27 \mathrm{mV}$ (right) and $0.26 \mathrm{mV}$ (left eye); almost unchanged at $80 \mathrm{lux}$. Values within normal limits.

signs of impaired cone function. The 1954 investigation showed that there was pronounced disturbance of the cone function since only a scotopic response could be obtained even at strong intensities of illumination (Fig. 3). The flicker E.R.G. examination in 1955 showed substantially the same picture as in 1954 .

The visual disturbances in this case, which constituted the only symptom for some years, could not be explained by routine eye examinations. No objective findings could be made apart from the initially very vague fundus findings. Owing to this uncertainty, highly varying conclusions were arrived at on different occasions, such as suspected $\bar{z}$ aggravation or hysteria, or, later on, the diagnosis of juvenile degeneration of the macula. Althoughp the falling values of the b-potential in single-flash E.R.G. would suggest a progressive lesion to the retinal function, nothing could be said with certaintyes since the values obtained were not actually patho f logical. Only the flicker E.R.G. proved the existence. of a wide-spread pathological process in the retina involving the cone function. Later on ataxie: symptoms appeared thus establishing the diagnosis? of hereditary ataxia. There is reason to believe that at a still later stage the patient will develop? distinct ophthalmoscopic changes in the retinaes possibly of the same type as had been observed ir her mother.

Case 2.-M. H-n, a woman, was born in 1936 (Nos? $254 / 51$ and $145 / 55)$. The patient's mother and maternat uncle, as well as her maternal grandmother and tw siblings of the maternal grandmother, suffered from: hereditary ataxia.

The patient herself had suffered from impaired visual acuity from the age of 7 , and her illness had gradually become worse during the last years. She now saw best in dim light. From the age of 17 , the patient had $\overrightarrow{\mathrm{e}} \times \overrightarrow{0}$ perienced difficulty in keeping her balance, and her was gradually becoming more unsteady.

A neurological examination in 1951, including pneurno $=$ encephalography, showed no abnormality. In 19

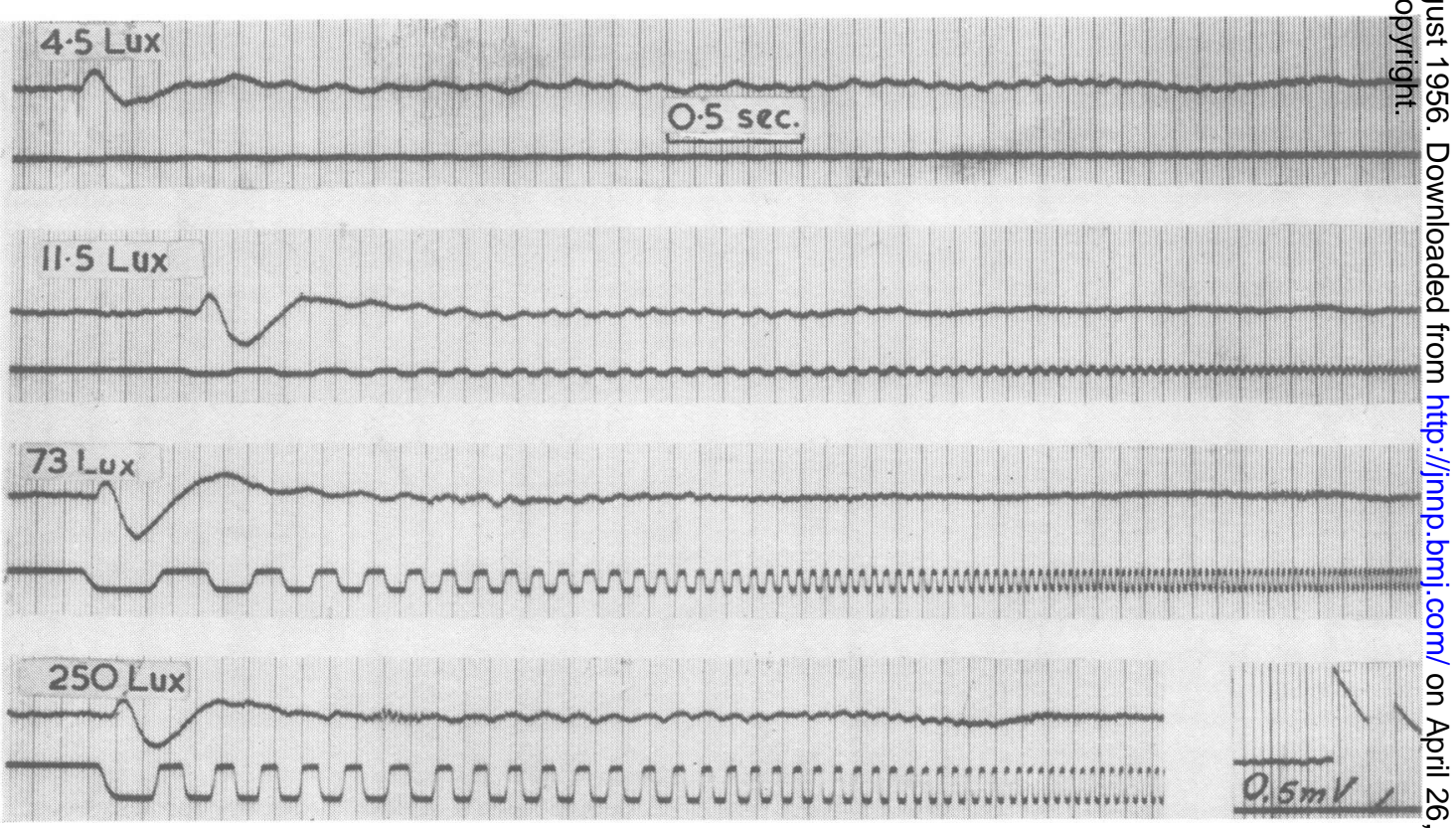

FIG. 3.-Case 1 (1954). Flicker E.R.G. at various intensities of stimulus illumination. Curves recorded simultaneously with curves in Fig. 2. All curves show scotopic flicker without signs of photopic potentials. Flicker fusion frequency about 15 per sec. at $4 \cdot 5$ lux about 20 per sec. at stronger intensities. 
examination revealed a slight deviation of gait to the right or left and a positive Romberg's sign. Diadochokinesis was impaired on both sides and there was slight dysmetria when trying to write. In the knee-heel test a slight tremor occurred on both sides. All muscular reflexes were lively, particularly in the legs, though not definitely increased and Babinski's sign was negative on both sides. Sensibility, gross power, and cranial nerves were normal. A caloric test resulted in slower nystagmus movements than usual. A radiograph of the skull and an E.E.G. revealed nothing abnormal. Her psychic state was normal. The internal organs were normal. She had no endocrine disorders, and tests on blood and cerebrospinal fluid for syphilis were negative.

In 1948, when the patient was 12 years old, an ophthalmological examination revealed a visual acuity of 0.5 for each eye; in 1951 the corresponding values were 0.1 to 0.2 (right eye) and 0.1 (left eye). The loss of visual acuity had become more severe during recent years, and at the last examination (1955) the values were just below 0.1 for each eye. On no occasion had it been possible to improve the conditions by using correcting glasses.

Examinations of the fundi in 1948 and 1951 showed nothing definitely pathological, but in 1954 and 1955 the papillae were of a yellowish pallor, and the vessels were narrow, in some places very narrow. Within the macula areas the pigment was perhaps somewhat agglomerated.

The limits of the visual fields for white were almost normal all the time. The light sense showed moderately pathological conditions. In 1954, the minimum perceptible was about $40 / 100.000$ lux and, in 1955, about $100 / 100 \cdot 000$ lux. The colour sense proved to be seriously defective at the anomaloscopic examination in 1954, the values being almost identical with those found in total colour blindness.

The following table shows the amplitude of the b-potential at a stimulant illumination of 80 lux in single flash E.R.G. (mean values) :

1951 (right) $0.29 \mathrm{mV}$ (left) $0.33 \mathrm{mV}$
1954 (right) $0.17 \mathrm{mV}$ (left) $0.18 \mathrm{mV}$

1955 (right) $0 \cdot 13 \mathrm{mV}$ (left) $0 \cdot 16 \mathrm{mV}$ (see Fig. 4)

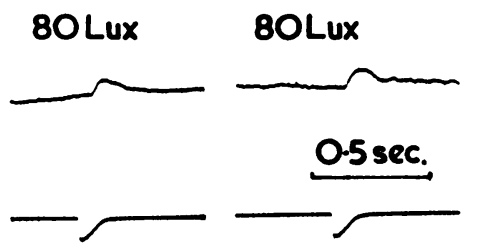

FIG. 4.-Case 2 (1955). Single flash E.R.G. of right and left eye. Calibration as in Fig. 2. Amplitude of b-waves, about $0.13 \mathrm{mV}$ (right) and $0.16 \mathrm{mV}$ (left). Subnormal E.R.G.

Hence the values obtained in 1951 are normal, the 1954 values are very probably abnormal, and those from 1955 are subnormal.

Flicker E.R.G.s were performed on two occasions, namely, in 1954 and 1955. Both times the curves were clearly pathological, the response being entirely scotopic even at high illumination intensities.

There is a definite resemblance in the clinical picture of this patient and that of Case 1. In both cases the ataxic symptoms were preceded by lowered visual acuity, the cause of which long remained doubtful. Flicker E.R.G.s revealed pathological conditions indicating an impaired cone function at a stage when a single flash E.R.G. still showed marginal values. In this case, however, even single-flash E.R.G.s yielded pathological values at the latest examination which may be interpreted as a spreading of the retinal affection to involve the rod function as well.

Case 3.-M. G. T-s, a woman, was born in 1936 (No. 630/54). The patient's family was explored over five generations. In all, 29 male and female members of this family, not counting the patient herself, had shown a clinical picture resembling that of the patient. She had inherited the disease through her mother (Case 5) and maternal grandmother, who were both affected. The maternal grandparents were first cousins. Some cases in another branch of the same family were investigated by Sjogren (1943, family 72).

From the age of about 11 the patient had experienced difficulty in keeping her balance and in speaking. Her balance had gradually become worse. During the same period she had been suffering from a progressive deterioration of vision and difficulties in distinguishing colours.

The patient did not go to a doctor until 1954 when she was 18. On neurological examination the gait was jerky, with frequent and long sidesteps, and with Romberg's test the patient reeled but did not fall. She showed slight dysmetria when performing finger-nose and knee-heel tests. Her speech was somewhat scanning. She had no aphasia. The muscular reflexes were very lively, especially in the legs, but not clearly increased. The Babinski sign was negative bilaterally. Sensibility, gross power, and cranial nerves were normal. An E.E.G. showed moderate generalized episodic abnormality. Her psychic state was normal. The internal organs were normal and there were no endocrine disturbances. Blood tests for syphilis were negative.

At an ophthalmological examination in 1954 visual acuity was scarcely 0.2 for each eye (with +1.5 cyl. $90^{\circ}$ ) and corneal astigmatism (as determined in the JavalSchiotz ophthalmometer) was + 3.0 D. $90^{\circ}$.

Fundi showed somewhat narrow arteries and a slight though coarsely granulated pigmentation of the maculae. The same type of possibly pathological pigmentation was also seen in the periphery.

The visual field for white showed normal limits. The light-sense values were pathological, though only slightly, minimum perceptible being about $20 / 100 \cdot 00$ lux. This figure, however, is rather uncertain, owing to the patient's being disturbed by subjective light phenomena. Though highly defective, the colour sense had not deteriorated to the degree described in Cases 1 and 2, but was of the same type. 
The single-flash E.R.G. (Fig. 5) was subnormal. The potential of the right eye was $0.12 \mathrm{mV}$ and of the left eye $0.10 \mathrm{mV}$ at an illumination of 80 lux. Somewhat lower values were obtained when using 20 lux: right eye, $0.09 \mathrm{mV}$, left, $0.08 \mathrm{mV}$. With 800 lux the deflection was very small: the b-potential was scarcely measurable and was preceded by a distinctly negative wave.

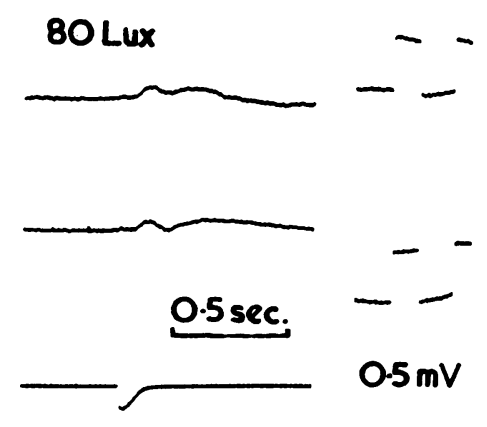

Fig. 5.-Case 3. E.R.G. of right and left eye. Amplitudes of b-waves, about $0.12 \mathrm{mV}$ and $0.10 \mathrm{mV}$, respectively. Subnormal E.R.G.

The flicker E.R.G. was mainly of the scotopic type but included scattered a-waves when the illumination was $\mathbf{3 0 0}$ lux or more. Flicker fusion frequency did not exceed 45 per second.

This patient did not present herself for examination until seven years after the onset of symptoms. The ophthalmoscopical picture indicated a retinal affection, most probably a macular degeneration. Single-flash E.R.G. indicated a widespread, severe functional lesion involving the rod function. Flicker E.R.G. showed the cone function to be also damaged, though less severely than in the two preceding cases, which is further consistent with the fact that both the colour sense and the visual acuity were a little better in the present case.

Case 4.-T. G., a man, was born in 1917 (Nos. 401/51 and 17/56). The patient's maternal grandmother, mother, a maternal aunt, two maternal uncles, and two first cousins were similarly affected.

At the age of 10 he had been forced to discontinue balancing exercises at school but had otherwise been in good health until about the age of 25 , when he had noticed difficulty in walking and diminution of visual acuity. The symptoms had steadily progressed and by the age of 31 he had been compelled to give up his job as a machine fitter.

Neurological examinations were made repeatedly during the years 1943 to 1951 . Examination in 1943 had revealed ataxic gait, incoordination of the arms and slight ataxia of the trunk. In 1951 he had, in addition, dysarthria and increased deep reflexes in both legs. A pneumoencephalogram at this time was essentially normal. Tests for syphilis on the blood and cerebrospinal fluid were negative.
A fresh neurological examination in 1956 showed tha the symptoms were more pronounced. The patient's gai was ataxic and spastic and he was able to walk only wit/5 the support of two persons though gross power was goode The Babinski sign was bilaterally positive. His speec was slow, slurred, scanning, and nasal. The tongued moved slowly and tended to deviate towards the lefe Changes in facial expression and eye movements were slow. No other abnormality of the cranial nerves wa. noted. The sensibility was normal. Skull radiographs? and an E.E.G. were normal.

Mental status showed no definite abnormality $\overrightarrow{\vec{p}}$ Examination of the heart, lungs, and abdomen reveale $\Phi$ no abnormality apart from radiological evidence of residues from an earlier pulmonary tuberculosis. $\mathrm{H} \frac{\bar{\sigma}}{\bar{\sigma}}$ had no endocrine disorder.

Ophthalmological examination was performed on fou occasions. The visual acuity was as follows:- के

\begin{tabular}{|c|c|c|}
\hline $\begin{array}{l}1945 \\
1948 \\
1951 \\
1956\end{array}$ & $\begin{array}{l}0 \cdot 6 \quad \text { (right) } \\
0 \cdot 3 \quad " \\
0 \cdot 1 \quad " \\
+1 / 50 ",\end{array}$ & $\begin{array}{l}0.5 \quad \text { (left) } \\
0.3 \quad ", \\
0.2 \\
+1 / 50 ",\end{array}$ \\
\hline
\end{tabular}

Vision was not improved with glasses.

Ophthalmoscopical examination showed normal fundథ̣ up to 1951. Examination in 1956 showed slight destruc $\overrightarrow{0}$ tion of the central part of the maculae with migratigin of the macular pigment towards the periphery and foveal reflex. The fundi were otherwise normal. papillae were of normal colour and no other evidefoge of pigment abnormality was seen.

The investigation in 1956 in addition showed mode $\overrightarrow{\text { titos }}$ concentric restriction of the visual fields for white. Light sense: minimum perceptible 8-10/100.000 lux, almost normal. The colour sense was markedly abnornt? At anomaloscopic examination this case was not quite like the others. The range of adjustment was very large more than 20 lines on the screw, and thus also differef from primary total colour blindness.

A single-flash E.R.G. showed that the mean amplitudes of the b-potential was $0.20 \mathrm{mV}$ with a stimulus of 80 luxo This is probably abnormal. A flicker E.R.G. was abnorō mal in both the right and the left eye: flicker fusio $\$$ frequency did not exceed $55 / \mathrm{sec}$. and was attained first with a stimulus of 700 lux. A light intensity of moro than 200 lux resulted in a few small photopic potentials in the record.

In this case impaired visual acuity and ataxie symptoms appear to have occurred about the same time. The ophthalmoscopical picture was normat up till 1951 in spite of marked impairment of. vision. Examination in 1956 showed moderats degeneration of the maculae. The E.R.G. revealed a widespread retinal degeneration. It is remarkable that the E.R.G. changes were actually not morê pronounced than in Cases 1, 2, and 3, despite the fact that he was examined at a more advance stage of the disease. This may possibly be explained by the fact that the maculae were more extensivelyg involved in this case. 
Case 5.-M. T-s, born in 1914, was the mother of Case 3.

The patient had begun to suffer from visual trouble and difficulties in keeping her balance about the age of 12 . Symptoms had become progressively worse and the patient had been admitted to a home in 1950 . Since 1952 she had been entirely bedridden.

The patient was examined in 1954. She was extremely emaciated. On physical examination the heart was normal. The patient could orientate herself in time and space but cooperated with the examiner only to the extent of answering "yes" and " no". She was capable of repeating isolated numerals and words of moderate length but could not contribute to the case history by giving anamnestic information. She was scarcely capable of lifting her feet from the bed. She had contractures of the hip and knee joints. The gross power of the hands was satisfactory. Movement of the hands and arms was incoordinated. Muscular reflexes were lively. The Babinski sign was positive bilaterally. The patient noticed pricking by a needle and also when her hands or feet were touched, and was aware of gross movements of her toe and finger joints. Her speech was unmodulated, drawling, and difficult to apprehend. She was capable of noticing smell, could eat, swallow, and cough; her voice was hoarse. She could hear whispering at more than three metres bilaterally.

An ophthalmological examination in 1954 showed light perception with uncertain localization, equal on both sides. The media of the eyes were clear. Both fundi displayed a considerable atrophy of the choroid and retina. The pigment was very scarce and agglomerated to form a loose network in the periphery, and there were isolated pigmented clumps akin to retinitis pigmentosa. The white colour of the sclera and the substantially thrombosed and sclerosed choroidal vessels were the principal features. The atrophies were especially distinct around the periphery and within a central area almost coinciding with the macula which, consequently, gave the impression of being punched. The papillae were pale and greyish, vessels narrow though not filamentous (Fig. 6).

Owing to the patient's bad general condition it was not possible to perform a complete ophthalmological investigation as in the preceding cases. However, Case 5 shows the advanced stage of retinal and choroidal atrophy, as illustrated in Fig. 6, to which the preceding cases may also be expected to proceed.

\section{Discussion}

The five cases reported here all showed distinct signs of ataxia, and it was possible to obtain reliable information on similar cases in the families concerned. The diagnosis of hereditary ataxia is believed to be accurate in each case. Although it does not seem necessary here further to classify the cases, all of them would fall under the category of hereditary ataxia of Pierre Marie's type.

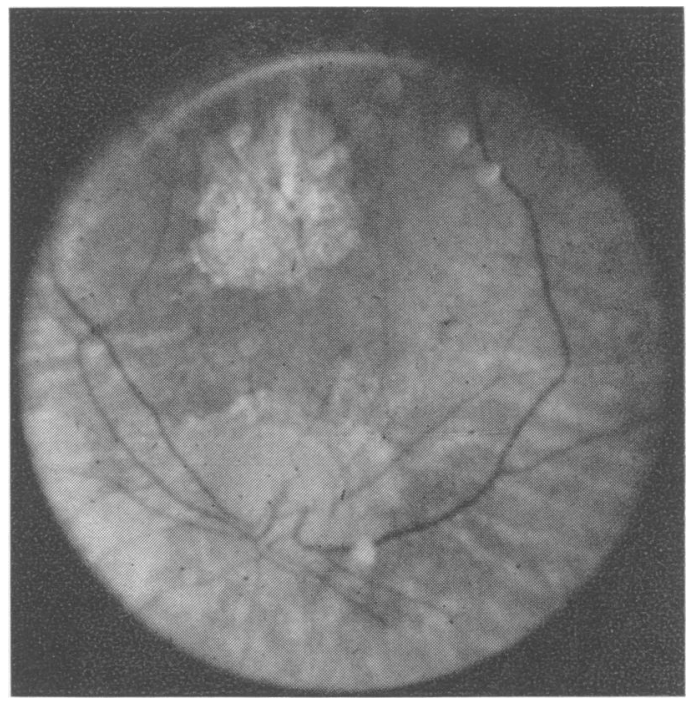

Fig. 6.-Case 5. Photograph of right fundus. The left fundus gave an identical picture.

The similarity in the symptoms and course of the disease in these five cases, although they belong to four different families, is one of their most striking features. They differ mainly in that they represent various stages. The examinations have revealed a widespread affection of the retina in each case and this is no doubt sufficient to account for the loss of vision. There seems to be no reason to presume the existence of lesions in the optic nerves or in more central parts of the visual pathways to explain the impairment of vision.

By means of E.R.G. it has been proved that the cases described here belong to a fairly well-defined and characteristic type of widespread progressive retinal degeneration. Both the cone and the rod systems are involved, though to a certain extent selectively, and it is suggested that the development of the disease is as follows. First, there is a disturbance of the cone function with progressive defect of colour vision and visual acuity, while the rod function remains relatively intact. Later, the rod system becomes affected as well and the disease proceeds towards a total cessation of the retinal function. The early attack on the cone system naturally explains the severe impairment of the central visual acuity and is, furthermore, reflected by the grave disturbance in colour vision.

It is tempting to make a comparison with retinitis pigmentosa, in which disease the rod function, in particular, is severely affected from the beginning. The main feature of the clinical picture is the lesion to the periphery of the retina resulting in contraction 
of the visual field and night-blindness, whereas the macula may continue to function almost satisfactorily for a considerable time. Hence the abovementioned degeneration of the retina in hereditary ataxia is of quite another type and clearly distinguished from the retinal degeneration known from retinitis pigmentosa.

It has not been possible to find in the literature on the subject any earlier cases of hereditary ataxia that have been examined by means of E.R.G. However, several cases of ophthalmoscopical fundus changes have been reported. In the material brought together by Sjogren (1943), which comprises 188 cases from 118 Swedish families, macular changes occurred in three cases and more extensive changes in the fundi in another three cases (70 Ea, $71 \mathrm{Ea}, 72 \mathrm{Ea}$, and $51 \mathrm{a}, 58 \mathrm{a}$, and $61 \mathrm{a}$, respectively). In some of these cases the fundus changes are probably due to inflammatory processes. One (72 Ea) of the cases showing degeneration of the maculae belongs to the same family as our Cases 3 and 5 .

Franceschetti and Klein (1948), in a critical survey of retinal degeneration in hereditary ataxia which included all cases published up to that date, have tried to exclude cases of inflammatory origin and cases where the diagnosis seemed doubtful. The remaining material consists of 22 cases of retinal degeneration belonging to 12 families. In some of them the fundus changes resembled those found in retinitis pigmentosa, in others there was a degeneration of the maculae. Often the clinical picture may be regarded as a combination of both types, and for these cases Franceschetti and Klein have coined the term " retinite pigmentaire atypique". In two of the 12 families there were extensive fundus changes resembling our findings in Case 5: in three siblings reported by Kapuściński (1934) and two first cousins reported by de Mello (1943) (quoted from Franceschetti and Klein, 1948). With the exception of the ophthalmological findings, however, the cases were quite different from those of the present study.

Franceschetti and Klein further discuss the question whether the simultaneous occurrence of retinal degeneration and hereditary ataxia is a random coincidence of two different diseases. However, they arrive at the conclusion that " les deux processus dégénératifs doivent etre considérés comme conséquence directe d'un facteur héréditaire commun".

Furthermore, it may be mentioned here that optic atrophy is said to be much more frequent than retinal degeneration in cases of hereditary ataxia. Of 100 cases, Sjogren (1943) found 22 cases of optic atrophy and, in addition, 17 cases where he found the papillae to be pale. In the material publishe by Bell and Carmichael, which includes all cases reported up to 1939, optic atrophy occurs in $9 \%$ (quoted from Greenfield, 1954).

It is not unique-nor is it very common so far as can be seen from the literature-that the impairese vision, as in our first two cases, constitutes the firs? symptom and causes the patient to see a docto several years before the onset of other symptoms. As for the retinal degeneration in hereditary ataxia $\overrightarrow{\bar{*}}$ Franceschetti and Klein (1948) point out as a characteristic feature that the visual symptoms first occur at the same time as other disturbances in the central nervous system.

It is a matter of great interest that for some year尺 at the beginning of the disease the visual disturbance could not be given a satisfactory explanation founde $f$ on the routine methods of ophthalmological examination. Also the vague ophthalmological findingsu sometimes resulted in a diagnosis of degeneration of the macula, and sometimes in a diagnosis of optic atrophy. When reviewing the cases already published it is striking how few objective findings are actualls made, even in cases of severe loss of vision. It:is also striking to find that the diagnosis of optic atrophy is sometimes based only on a sligho discoloration of the papilla, as has already been pointed out by Bell and Carmichael (1939). I is possible that some of the cases of impaired visga产 acuity hitherto attributed to primary optic atrojhy? ought rather to come under the category of retinat degeneration with consecutive optic atrophy. Tilis would imply that degeneration of the retina is more common as a constituent of hereditary ataxia thar has so far been believed. In future investigations into the problem of the origin of visual deterioration in hereditary ataxia, E.R.G. examinations of furtheo cases should be of great value.

\section{Summary}

Five cases of hereditary ataxia with deterioration? of vision are described. The cases belonged to foup different families.

In four of the cases, the clinical examinations included single-flash electroretinography (single:flash E.R.G.) and flicker electroretinography. (flicker E.R.G.), thereby revealing extensive retina's lesions. In these four cases, ophthalmologicaB routine methods could not account for the impairedo vision. In three of the cases, flicker E.R.G. was pathological at a stage when single-flash E.R.G음 was normal or showed marginal values. In the fifthcase, ophthalmoscopy revealed an advanced retinato degeneration.

Taken together, the results show that a com-N paratively uniform type of extensive progressive 
retinal degeneration prevailed in the cases described. Both the cone and the rod systems were involved, though to a certain extent selectively, and it is suggested that the development of the disease is as follows. First, there is a disturbance of the cone function with progressively defective colour vision and visual acuity, while the rod function remains relatively intact. Later, the rod system becomes affected as well and the disease proceeds towards a total cessation of the retinal function.

Retinal degeneration in hereditary ataxia is probably more frequent than previously believed and may have constituted the cause of visual deterioration in some of the cases where hitherto it has been ascribed to primary optic atrophy.

\section{REFERENCES}

Bell, J., and Carmichael, E., A. (1939). "On Hereditary Ataxia and Spastic Paraplegia." Treas. hum. Inher., vol. 4, pt. 3.

Bogaert, L. van (1948). Rev. Oto-neuro-ophtal., 20, 415.

Dodt, E., and Wadensten, L. (1954). Acta ophthal. (Kbh.), 32, 165 .

Franceschetti, A., and Klein, D. (1948). Rev. Oto-neuro-ophtal., $20,109$.

Granit, R. (1947). Sensory Mechanisms of the Retina. Oxford University Press, London.

Greenfield, J. G. (1954). The Spino-Cerebellar Degenerations. American Lecture Series.] Blackwell, Oxford.

Kapuściński, W. (1934). Ber. dtsch. ophthal., Ges., 50, 13.

Karpe, G. (1945). Acta ophthal. (Kbh.). Suppl. 24.

- (1948). Docum. ophthal. (Paris), 2, 268.

(1955). Personal communication.

Mel, and Tansley, K. (1948). J. physiol. (Lond.), 107, 272.

Mello, A. R. de (1943). Arch. brasil. Med., 33, 1. Quoted by Franceschetti and Klein (1948), p. 133.

Sjogren, T. (1943). "Klinische und erbbiologische Untersuchungen über die Hereoataxien." Acta psychiat. neurol. Suppl. 27. Munksgaard, Copenhagen.

Wadensten, L. (1954). Acta. ophthal. (Kbh.), 32, 743.

_- (1956). Ibid. In the press. 